\title{
PENDEKATAN EDUKATIF TENTANG BREAST CARE PADA IBU HAMIL DAN NIFAS DI KLINIK BPM MARIANA BINJAI
}

\author{
Lasma Rina Efrina Sinurat ${ }^{1}$, Rosetty Sipayung ${ }^{2}$, Agnes Silvina Marbun ${ }^{3}$ \\ 1,2,3 Universitas Sari Mutiara Indonesia \\ Disubmit: 10 Maret 2021 Diterima: 17 April $2021 \quad$ Diterbitkan: 04 Agustus 2021 \\ Email Korespondensi: lasma.rina.sinurat13@gmail.com
}

\begin{abstract}
ABSTRAK
Perawatan payudara sangat penting dilakukan selama hamil sampai masa menyusui. Hal ini karena payudara merupakan satu-satunya penghasil ASI yang merupakan makanan pokok bayi baru lahir sehingga harus dilakukan sedini mungkin. Breast care bertujuan untuk memelihara kebersihan payudara, memperbanyak atau memperlancar pengeluaran ASI.Tujuan pengabdian masyarakat ini adalah untukmempersiapkan ibu hamil dan nifas agar dalam kondisi baik saat menyusui bayinya dan agar mampu mendemontrasikan perawatan payudara dengan benar secara mandiri di rumah. Adapun metode pengabdian masyarakat ini dengan pendekatan edukatif tentang perawatan payudara pada ibu hamil dan nifas di klinik BPM Mariana Binjai dalam bentuk ceramah dan tanya jawab serta melakukan demonstrasi perawatan payudara. Hasil dari pengabdian masyarakat ini adalah menjaga kebersihan payudara terutama kebersihan puting susu, melenturkan dan menguatkan puting susu sehingga memudahkan bayi untuk menyusu, merangsang kelenjar-kelenjar air susu sehingga produksi ASI banyak dan lancar, dapat mendeteksi kelainankelainan payudara secara dini dan melakukan upaya untuk mengatasinya dan mempersiapkan mental (psikis) ibu untuk menyusui. Diharapkan setelah dilakukan pendekatan edukatif ini ibu hamil dan nifas pengetahuannya semakin meningkat dan mampu mempersiapkan pemberian ASI eksklusif kepada bayinya.
\end{abstract}

Kata Kunci : edukasi, breast care, ibu hamil dan nifas

\section{ABSTRACT}

Breast care is very important during pregnancy until breastfeeding. This is because the breast is the only producer of breast milk which is the staple food for newborns, so it must be done as early as possible. Breast care aims to maintain breast hygiene, increase or facilitate breastfeeding. The aim of this community service is to prepare pregnant and childbirth mothers to be in good condition when breastfeeding their babies and to be able to demonstrate proper breast care independently at home. The community service method uses an educational approach on breast care for pregnant and postpartum mothers at the BPM Mariana Binjai clinic in the form of lectures and questions and answers as well as conducting breast care demonstrations. The result of this community service is maintaining breast cleanliness, especially nipple hygiene, flexing and strengthening the nipple so that it makes it easier for babies to breastfeed, stimulating the milk glands so that milk production is large and smooth, can detect breast abnormalities early and make efforts to overcome it and prepare 
the mother mentally (psychologically) to breastfeed. It is hoped that after this educational approach, pregnant and post-partum women will have increased knowledge and be able to prepare exclusive breastfeeding for their babies.

\section{Keywords : education, breast care, pregnant women and postpartum}

\section{PENDAHULUAN}

Air Susu Ibu (ASI) merupakan makanan pertama, utama dan terbaik bagi bayi yang bersifat alamiah dan mengandung berbagai zat gizi yang dibutuhkan dalam proses pertumbuhan dan perkembangan bayi baru lahir dimana bertujuan untuk menurunkan angka kematian. Pemberian ASI eksklusif dapat meminimalisir banyaknya kasus kurang gizi pada bayi dimasa periode emas sekaligus periode kritis tumbuh kembang bayi (Sari \& Ernawati, 2016).

Menurut data Survei Demografi dan Kesehatan Indonesia (SDKI) tahun 2010 bahwa 55 \% ibu menyusui mengalami mastitis dan putting susu lecet. Putting susu lecet terjadi karena dua faktor, yaitu karena kondisi putting yang jarang dibersihkan dan posisi ibu saat menyusui yang kurang benar, hal tersebut disebabkan kurangnya perawatan payudara selama kehamilan. Demi keberhasilan menyusui, payudara memerlukan perawatan sejak dini secara teratur. Perawatan selama kehamilan bertujuan agar selama masa menyusui kelak produksi ASI cukup, tidak terjadi kelainan pada payudara dan agar bentuk payudara tetap baik setelah menyusui (Badan Pusat Statistik et al., 2013)

Perawatan payudara sangat penting dilakukan selama hamil sampai masa menyusui. Hal ini karena payudara merupakan satu-satunya penghasil ASI yang merupakan makanan pokok bayi baru lahir sehingga harus dilakukan sedini mungkin. Dimana produksi ASI akan merangsang kelenjar-kelenjar air susu melalui pemijatan (Harahap, 2017)

Perawatan payudara atau sering disebut Breast Care bertujuan untuk memelihara kebersihan payudara, memperbanyak atau memperlancar pengeluaran ASI. Tujuan perawatan untuk memperlancar produksi ASI dengan merangsang kelenjar-kelenjar air susu melalui pemijatan, mencegah bendungan ASI atau pembengkakan payudara, melenturkan dan menguatkan putting (Fatmawati et al., 2019).

Perawatan payudara pada ibu hamil dan nifas merupakan perawatan yang sebaiknya dilakukan untuk mempersiapkan payudara agar dalam kondisi baik saat menyusui bayinya, meliputi perawatan kebersihan payudara baik sebelum maupun sesudah menyusui. Perawatan puting susu yang lecet dan merawat puting susu agar tetap lemas, tidak keras, dan tidak kering (Damanik, 2020).

Faktor yang menyebabkan seorang ibu hamil tidak melakukan perawatan payudara karena kurangnya informasi yang didapat dari tenaga kesehatan, adanya rasa takut dan malas dan ketersediaan waktu untuk melakukan perawatan payudara selama masa kehamilan dalam trimester III. Perawatan payudara sangatlah penting dilakukan pada trimester III supaya tidak terjadi komplikasi pada saat menyusui bayinya nanti (Sari \& Ernawati, 2016).

Sepanjang kunjungan ibu hamil dan nifas di klinik BPM (Balai Praktek Mandiri) Mariana Binjai ada kurang lebih 15 \% (3 orang) ibu hamil dan nifas mengalami bendungan ASI. Masih banyaknya ibu hamil dan nifas yang tidak melakukan perawatan payudara disebabkan karena berbagai faktor yang mempengaruhi seperti ketidaktahuan dan ketidakmauan ibu melakukannya karena kurangnya kesadaran akan pentingnya merawat payudara dan tidak 
adanya waktu karena kesibukan sehari-hari. Selain itu juga dipengaruhi oleh kecemasan ibu yang dapat menyebabkan stres sehingga pengaruh ke hormon kortisol meningkat dan berdampak ke penurunan hormon oksitosin sehingga pengeluaran ASI tidak lancar.

Hasil studi pendahuluan yang dilakukan di BPM (Balai Praktek Mandiri) Mariana Binjai didapatkan data ibu hamil trimester III sebanyak 7 orang. Dari hasil wawancara diketahui bahwa 4 ibu hamil tidak mengetahui cara melakukan perawatan payudara dengan benar, dan 3 ibu hamil hanya sebatas mengetahui tetapi tidak pernah melaksanakan perawatan payudara karena merasa tidak ada kelainan di payudaranya.

\section{MASALAH}

Pelaksanaan pengabdian kepada masyarakat tentang perawatan payudara di klinik BPM (Balai Praktek Mandiri) Mariana Binjai ada kurang lebih $15 \%$ ibu hamil dan nifas mengalami bendungan ASI. Masih banyaknya ibu hamil dan nifas yang tidak melakukan perawatan payudara disebabkan karena berbagai faktor yang mempengaruhi seperti ketidaktahuan dan ketidakmauan ibu melakukannya karena kurangnya kesadaran akan pentingnya merawat payudara dan tidak adanya waktu karena kesibukan sehari-hari. Selain itu juga dipengaruhi oleh kecemasan ibu yang dapat menyebabkan stres sehingga pengaruh ke hormon kortisol meningkat dan berdampak ke penurunan hormon oksitosin sehingga pengeluaran ASI tidak lancar.

Hasil studi pendahuluan yang dilakukan di BPM (Balai Praktek Mandiri) Mariana Binjai didapatkan data ibu hamil trimester III sebanyak 7 orang. Dari hasil wawancara diketahui bahwa 4 ibu hamil tidak mengetahui cara melakukan perawatan payudara dengan benar, dan 3 ibu hamil hanya sebatas mengetahui tetapi tidak pernah melaksanakan perawatan payudara karena merasa tidak ada kelainan di payudaranya.

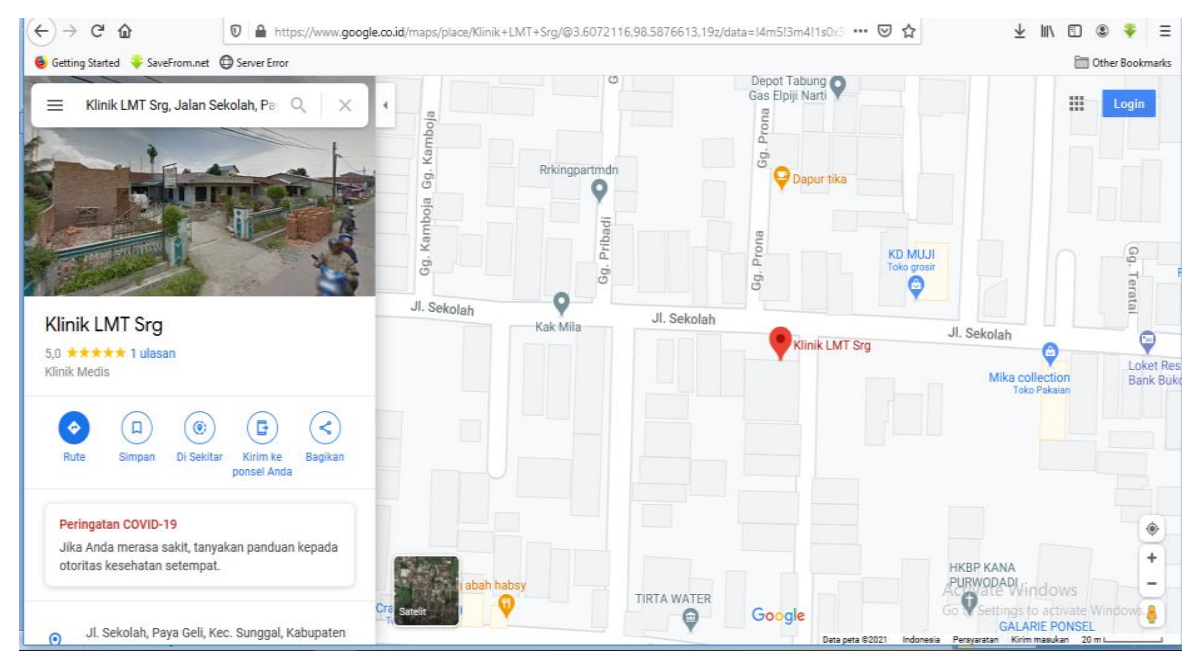

Gambar 2.1 Lokasi Penyuluhan Kesehatan Klinik LMT Siregar Binjai 


\section{METODE}

1. Tahap Persiapan

Awal kegiatan pengabdian masyarakat ini adalah melakukan kontrak kepada peserta penyuluhan yaitu ibu hamil dan nifas, baik kontrak waktu dan kesediaan para peserta penyuluhan. Persiapan awal lain adalah alat-alat yang digunakan yaitu pantom breast care, handuk dan air hangat dan untuk penyajian persiapan alat-alat seperti laptop, Liquid crystal display (LCD), layar proyektor, sound system, microfon. Pembuatan leaflet untuk materi breast care atau perawatan payudara dibuat dengan menggunakan materi yang mudah dimengerti dan menggunakan gambar-gambar.

2. Tahap Pelaksanaan

Pada tahap pelaksanaan pendekatan edukatif tentang breast care ini ibu hamil dan nifas terlebih dahulu mengisi daftar hadir yang diberikan oleh tim pengabdian masyarakat dan beberapa pertanyaan yang diajukan oleh tim fasilitator yang berupa usia ibu, tingkat pendidikan ibu, pelaksanaan breast care di rumah dan alasan ibu hamil kenapa tidak melakukan breast care di rumah kemudian dilanjutkan penyajian video dan penyuluhan melalui pendekatan edukatif tentang breast care. Tim pengabdian masyarakat juga membagikan leaflet dan memutarkan video agar mudah dimengeti dan mempraktekkan langsung perawatan payudara (breast care) menggunakan manikin/boneka oleh tim pengabdian kepada masyarakat.

3. Evaluasi

\section{a. Struktur}

Ibu hamil dan nifas yang hadir sebanyak 28 orang dengan kategori ibu hamil trimester III sebanyak 13 orang dan ibu nifas kurang lebih 2-4 minggu paska melahirkan sebanyak 15 orang. Tim pengabdian masyarakat berbagi tugas dimana 1 orang penyaji materi dan video sekaligus yang membawakan acara pendekatan edukatif ini, 1 orang bertugas sebagai fasilitator diantara peserta penyuluhan dan 1 orang bertugas sebagai notulen dan untuk mendokumentasikan kegiatan pengabdian masyarakat ini. Tim juga melibatkan 2 orang mahasiswa untuk membantu tim agar kegiatan pengabdian masyarakat tentang breast care ini berjalan dengan baik.

b. Proses

Pelaksanaan kegiatan ini dilaksanakan sesuai jadwal dari pukul $16.00 \mathrm{~s} / \mathrm{d} 17.45$ wib.

c. Metode Evaluasi

Metode evaluasi dilakukan pada awal dan akhir penyampaian materi dan para ibu hamil dan nifas mampu memahami dan menjelaskan kembali terkait breast care atau perawatan payudara yaitu memahami dan mengerti tentang definisi, tujuan dan manfaat, akibat jika tidak dilakukan breast care /perawatan payudara, penatalaksanaan, hal-hal yang perlu diperhatikan dan mampu mempraktekkan breast care /perawatan payudara di rumah secara mandiri atau dibantu oleh anggota keluarga lain pada ibu hamil dan nifas. 


\section{HASIL DAN PEMBAHASAN}

Pelaksanaan pengabdian masyarakat dengan topik Pendekatan Edukatif Tentang Breast Care Pada Ibu Hamil Dan Nifas di Klinik BPM (Balai Praktek Mandiri) Mariana Binjai, akan diuraikan pada hasil pengabdian masyarakat sebagai berikut:

Tabel 4.1. Distribusi Karakteristik Ibu Hamil dan Ibu Nifas di Klinik BPM (Balai Praktek Mandiri) Mariana Binjai $(\mathrm{n}=28)$

\begin{tabular}{|c|c|c|c|c|c|}
\hline \multicolumn{3}{|c|}{ Karakteristik Ibu Hamil ( $\mathrm{n}=13)$} & \multicolumn{3}{|c|}{ Karakteristik Ibu Nifas $(n=15)$} \\
\hline Usia Ibu Hamil & $\mathrm{n}$ & $\%$ & Usia Ibu Nifas & $\mathrm{n}$ & $\%$ \\
\hline$<35$ tahun & 9 & 69,2 & $<35$ tahun & 10 & 60 \\
\hline$>35$ tahun & 4 & 30,8 & $>35$ tahun & 6 & 40 \\
\hline $\begin{array}{l}\text { Tingkat Pendidikan Ibu } \\
\text { Hamil }\end{array}$ & & & $\begin{array}{l}\text { Tingkat Pendidikan Ibu } \\
\text { Nifas }\end{array}$ & & \\
\hline SMP & 2 & 15,4 & SMP & 3 & 20 \\
\hline SMA & 10 & 76,9 & SMA & 8 & 53,3 \\
\hline Perguruan Tinggi & 1 & 7,7 & Perguruan Tinggi & 4 & 26,7 \\
\hline $\begin{array}{l}\text { Pelaksanaan Perawatan } \\
\text { Payudara di Rumah }\end{array}$ & & & $\begin{array}{l}\text { Pelaksanaan } \\
\text { Perawatan Payudara di } \\
\text { Rumah }\end{array}$ & & \\
\hline $\begin{array}{l}\text { Pernah } \\
\text { Tidak Pernah }\end{array}$ & $\begin{array}{c}1 \\
12\end{array}$ & $\begin{array}{l}7,7 \\
92,3\end{array}$ & $\begin{array}{l}\text { Pernah } \\
\text { Tidak Pernah }\end{array}$ & $\begin{array}{c}3 \\
12\end{array}$ & $\begin{array}{l}20 \\
80\end{array}$ \\
\hline $\begin{array}{l}\text { Alasan Ibu Tidak } \\
\text { Melakukan Perawatan } \\
\text { Payudara }\end{array}$ & & & $\begin{array}{l}\text { Alasan Ibu Tidak } \\
\text { Melakukan Perawatan } \\
\text { Payudara }\end{array}$ & & \\
\hline Bekerja & 3 & 25 & Bekerja & 5 & 11,7 \\
\hline Tidak Tahu & 9 & 75 & Tidak Tahu & 7 & 58,3 \\
\hline
\end{tabular}

Berdasarkan tabel 4.1 ini dapat dilihat bahwa karakteristik ibu hamil dan nifas tentang perawatan payudara mayoritas berusia $<35$ tahun sebanyak $69,2 \%$ dan $60 \%$. Karakteristik tingkat pendidikan ibu hamil dan nifas mayoritas SMA sebanyak $76,9 \%$ dan $53,3 \%$. Karakteristik pelaksanaan perawatan payudara di rumah pada ibu hamil dan nifas mayoritas tidak pernah melakukan breast care sebanyak $92,3 \%$ dan $80 \%$. Serta karakteristik alasan ibu tidak melakukan perawatan payudara di rumah pada ibu hamil dan nifas mayoritas tidak tahu sebanyak $75 \%$ dan $58,3 \%$.

Metode pelaksanaan kegiatan pendekatan edukatif ini dengan menggunakan ceramah dan tanya jawab dan evaluasi kepada peserta penyuluhan. Pendekatan edukatif ini dilaksanakan pada tanggal 12 Desember 2020. Berikut gambar pelaksanaan pendekatan edukatif ini :
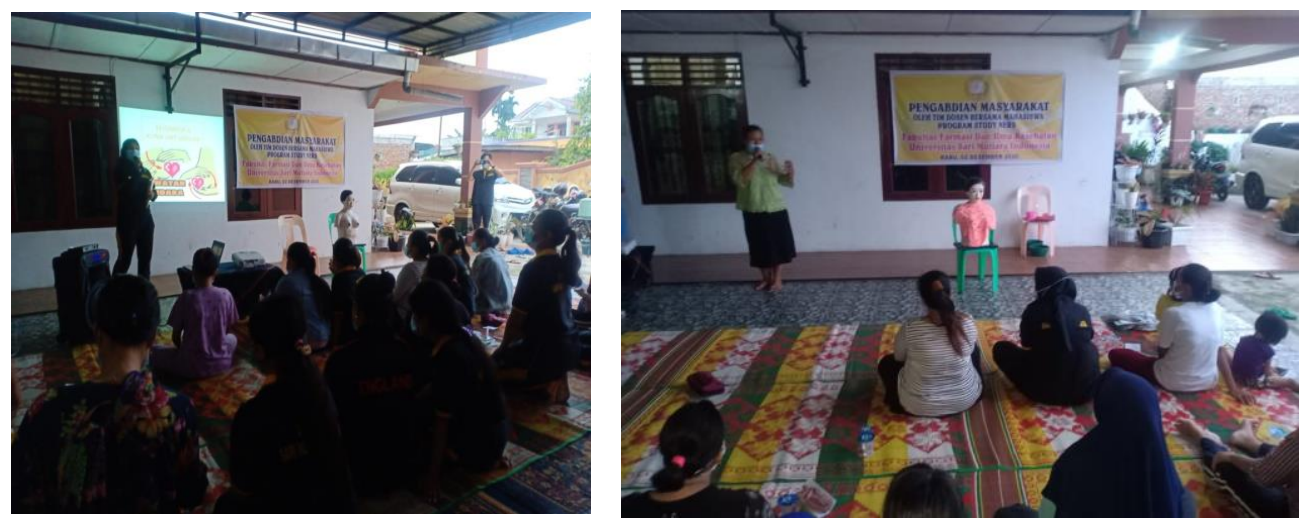

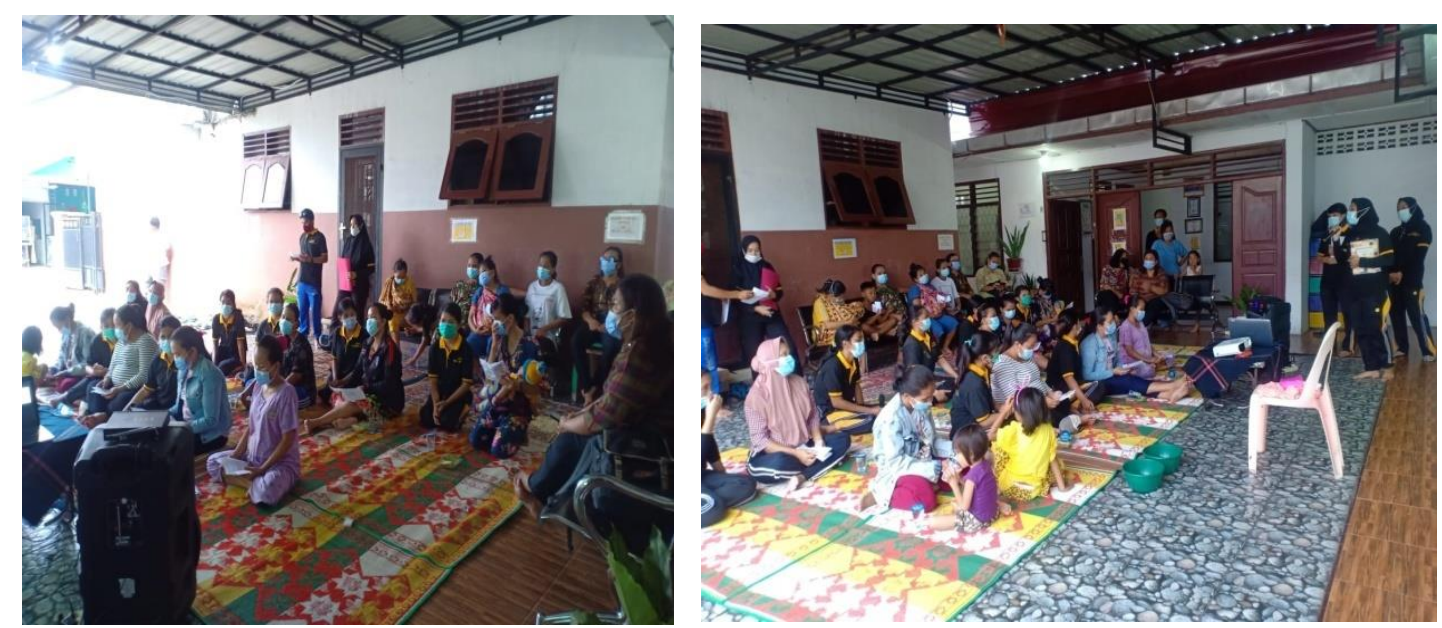

Gambar 4.1 Pendekatan Edukatif Breast Care

Pengetahuan ibu didapatkan dari proses pendidikan yang ibu dapatkan selama ini, sebab semakin tinggi tingkat pendidikan seseorang maka daya pikir rasionalnya akan semakin tajam dan matang. Berdasarkan Tanya jawab yang dilakukan didapatkan bahwa mayoritas ibu hamil dan nifas (10 orang dan 8 orang) berpendidikan SMA yang tahap berpikirnya masih pada tahap tahu dan memahami. Pada tahap ini kondisi berpikir ibu masih mudah dipengaruhi oleh orang lain, seperti keluarga dan teman dekatnya. Terlebih lagi adanya sumber informasi yang bisa didapat dari sumber media cetak, elektronik dan tenaga kesehatan yang berpengaruh pada pola pikir ibu atau persepsi ibu tentang perawatan payudara yang berakibat kesalahan pemahaman tentag perawatan payudara (Prawita \& Salima, 2018).

Perawatan payudara dimasa menyusui sangat berpengaruh pada proses pemberian ASI. Payudara yang bersih, sehat, terawat dengan baik dapat membantu melancarkan produksi ASI, sehingga pemberian ASI menjadi lebih mudah dan bayi lebih nyaman saat menyusu. Pelaksanaan Breast Care pasca persalinan dimulai sedini mungkin yaitu 1-2 hari sesudah bayi dilahirkan. Adanya faktor dari informasi yang salah tentang perawatan payudara dan rasa tidak nyaman atau sakit selama melaksanakan perawatan payudara membuat ibu nifas tidak mau melakukannya (Prawita \& Salima, 2018).

Salah satu upaya peningkatan produksi ASI dapat dilakukan yaitu dengan melakukan perawatan payudara pada ibu hamil dan nifas. Perawatan payudara sangat bermanfaat untuk menjaga kebersihan payudara diantaranya kebersihan pada puting susu agar terhindar dari infeksi karena penumpukan kotoran dan melunakkan serta memperbaiki bentuk puting susu. Pada saat proses menyusui berjalan dengan baik maka akan merangsang kelenjar-kelenjar pada payudara serta merangsang hormon prolaktin dan oksitosin untuk meningkatkan produksi ASI dan kelancaran ASI. Akan tetapi, ibu yang mengalami stres, pikiran tertekan, tidak tenang, cemas, sedih dan tegang juga sangat mempengaruhi hormon oksitosin karena pada saat terjadi kecemasan maka akan mengeluarkan hormon kortisol yang akan menghambat pengeluaran atau kelancaran ASI. Jadi, Ibu menyusui yang mengalami kecemasan akan sedikit mengeluarkan ASI dibandingkan ibu yang tidak mengalami kecemasan (Rahmi et al., 2020). 
Hasil penelitian ini, sejalan dengan hasil penelitian Qiftiyah tahun 2018 didapatkan bahwa ada hubungan antara tingkat kecemasan dengan kelancaran pengeluaran ASI pada ibu post partum primipara. Salah satu upaya yang dilakukan oleh ibu menyusui agar ASI tetap lancar yaitu mulai dari niat atau keinginan ibu yang kuat untuk memberikan ASI pada bayinya. Motivasi dari keluarga yang kuat juga akan berpengaruh terhadap fisik dan emosi ibu untuk melancarkan dan meningkatkan volume ASI, karena dukungan dari orang-orang terdekat, ibu menyusui terhindar dari kecemasan sehingga terciptakan suasana yang nyaman di dalam keluarga dan ibu merasa rileks dan nyaman pada saat menyusui bayinya. Sebaliknya jika ibu merasa cemas dan stress akan menghambat kelancaran pengeluaran ASI (Qiftiyah, 2018).

Demikin juga penelitian yang dilakukan oleh (Nurdiantini, I., Prastiwi, S., \& Nurmaningsari et al., 2017) didapatkan hasil bahwa ada hubungan perawatan payudara dengan kelancaran ASI pada ibu postpartum. Apabila ibu melakukan perawatan payudara dengan baik maka akan meningkatkan dan menambah volume ASI. Perawatan payudara perlu diperhatikan dalam proses laktasi yang seringkali menjadi solusi bagi ibu nifas, karena pada hari-hari pertama kelahiran merupakan masa penyesuaian yang berat dan seringkali ASI tidak lancar karena pengaruh hormon progesteron. Perawatan payudara bertujuan agar payudara senantiasa bersih dan mudah dihisap oleh bayi dan ibu merasa nyaman, rileks serta bahagia dengan kehadiran bayinya.

\section{KESIMPULAN}

Dapat disimpulkan bahwa breast care atau perawatan payudara dilakukan guna mempersiapkan ibu hamil dan nifas saat menyusui bayinya. Kelancaran ASI sangat penting dalam memenuhi kebutuhan bayi. Air Susu Ibu (ASI) adalah makanan yang terbaik bagi bayi yang baru lahir. ASI mencukupi kebutuhan gizi bayi hingga berusia 6 bulan. Artinya tanpa tambahan makanan apapun, kebutuhan nutrisi bayi sudah tercukupi lewat ASI.

\section{DAFTAR PUSTAKA}

Adam, S., Korompis, M., \& Alow, G. (2016). Perawatan Payudara Pada Masa Kehamilan Dan Pemberian Asi Eksklusif. In Jurnal Ilmiah Bidan (Vol. 4, Issue 2, p. 227076).

Badan Pusat Statistik, Badan Koordinasi Keluarga Berencanan Nasional, Departemen Kesehatan, \& Macro International. (2013). Survei Demografi dan Kesehatan Indonesia 2012. Sdki, 16. https://doi.org/10.1111/j.1471-0528.2007.01580.x

Damanik, V. A. (2020). Hubungan Perawatan Payudara Dengan Kelancaran Asi Pada Ibu Nifas. Jurnal Keperawatan Priority, 3(2), 13-22. https://doi.org/10.34012/jukep.v3i2.959

Fatmawati, L., Syaiful, Y., \& Wulansari, N. A. (2019). PENGARUH PERAWATAN PAYUDARA TERHADAP PENGELUARAN ASI IBU POST PARTUM ( The Effect of Breast Care in the Milk Output of Post Partum Mother ) Lilis Fatmawati *, Yuanita Syaiful *, Nur Afni Wulansari ** PENDAHULUAN Air Susu Ibu ( ASI ) Perawatan payudara seb. Journal of Ners Community, 10(November), 169-184. http://journal.unigres.ac.id/index.php/JNC/article/view/904/0 
Harahap, R. A. (2017). Analisis Perilaku Ibu Hamil Dalam Melakukan Perawatan Payudara Di Klinik Khadijah Lupuk Pakam. Jurnal JUMANTIK, 2(2), 42-53.

Nurdiantini, I., Prastiwi, S., \& Nurmaningsari, T., Fatonah, S., Rihiantoro, T., Irawan, H., \& Ari, S. (2017). Hubungan Perawatan Payudara Terhadap Kelancaran ASI Pada Ibu Post-Partum Di Kelurahan Tlogomas Kecamatan Lowokwaru Kota Malang. Journal Nursing News, 2(1), 3137.

Permenkes (2019) "Peraturan Menteri Kesehatan Republik Indonesia," Journal of Chemical Information and Modeling, 53(9), hal. 1689-1699. doi: $10.1017 /$ CBO9781107415324.004.

Prawita, A. A., \& Salima, M. (2018). Hubungan Pengetahuan dan Sikap Ibu Nifas tentang Perawatan Payudara dengan Pelaksanaan Perawatan Payudara di Klinik Pratama Niar Medan. Jurnal Bidan Komunitas, 1(3), 133. https://doi.org/10.33085/jbk.v1i3.3991

Qiftiyah, M. (2018). Studi Tingkat Kecemasan Ibu Post Partum Terhadap Kelancaran ASI Pada Ibu Nifas Hari Ke-5 (Di BPM Asri Dan Polindes Permata BundaTuban). LPPM AKES Rajekwesi Bojonegoro, 8(2), 39-43.

Rahmi, J., Romlah, S. N., Ramadihina, A. R., \& Sari, I. P. (2020). Pengaruh Perawatan Payudara Terhadap Kelancaran Asi Dan Tingkat Kecemasan Pada Ibu Nifas. Edu Masda, 4(1), 49-55.

Safitri, I., Ariana, S., \& Wijayanti, A. C. (2018). Hubungan Perawatan Payudara Dengan Kelancaran Produksi ASI. 8(1), 13-19.

Sari, L., \& Ernawati, S. (2016). Pengetahuan Ibu Hamil Trimester III tentang Perawatan Payudara di Klinik Pratama Bina Sehat Kasihan, Bantul, Yogyakarta. Jurnal Ners Dan Kebidanan Indonesia, 3(1), 26. https://doi.org/10.21927/jnki.2015.3(1).26-32 